\title{
Futurists predict body swaps for planet hops
}

Geoff Brumfiel, Washington

Direct brain-to-brain communication and the transfer of minds between bodies seem more like the stuff of Hollywood movies than of government reports - but these are among the advances forecast in a recent report by the US National Science Foundation and Department of Commerce.

"Improving human performance has been a dream for centuries," says Mihail Roco, chairman of the government-funded National Nanotechnology Initiative, and lead author of the study. Dreams of herculean strength and everlasting life are currently constrained by the limitations of the human body. But the report - Converging Technologies for Improving Human Performance, released on 8 July - says that the convergence of nanotechnology, biotechnology, computer science and cognitive science may help to break those limits in the next 20 years.

Combining these fields will allow human technology to be seamlessly integrated with biological systems, say the authors, who come from a mixture of academic and industrial backgrounds. They suggest it might be possible to use nanorobots to repair damaged or defective body parts, or to improve peoples' brains so that our memories never fade.

The report doesn't stop there. If technology
Having delivered our report, I can now reveal that I come from the future, to which I now return - farewell!)

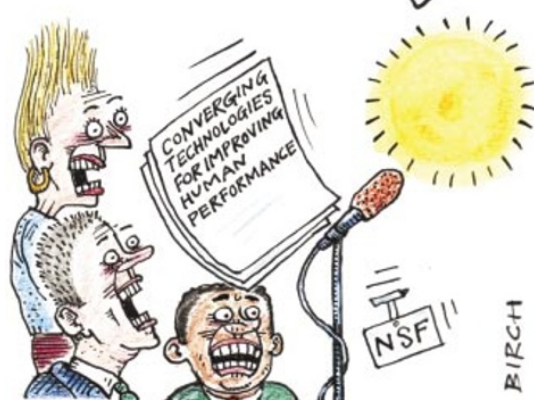

and biological systems could be integrated absolutely, the authors claim it might be possible to 'upload' your mind from your body and transmit it to another world, such as Mars. Once there, you could download your mind into a different body and experience the planet. And by periodically uploading your mind to new bodies, it suggests, you could live forever.

Other futurist furrows ploughed in the report include the idea of individuals communicating using brain implants, and computer models that could predict how societies behave and evolve. The authors propose that such models could be used to eliminate trends such as fundamentalism or fascism.

Presidential science adviser John Marburger acknowledges that some of ideas may seem a little extreme, but he believes they cannot be ignored. "Topics that seemed far out even a few years ago are much closer than we anticipated," he says. "It would be irresponsible for us to dismiss these ideas." Rita Colwell, director of the National Science Foundation, agrees. "It's just a lovely report," she says. "It provides an awfully good justification for the investments we're making now."

But not everyone is convinced. "I can't imagine what they plan to do with the damn thing," says Bob Park, director of public information at the American Physical Society. $\mathrm{He}$ believes that the ideas are too far-out to have much of an impact on current research funding. "You can't make plans for technology so many years in advance," says Park.

Others say that social behaviour is too complex to be reduced to a set of discrete variables. Modelling can help social scientists to understand trends, says Don Brenneis, president of the American Anthropological Association and a researcher at the University of California, Santa Cruz, but it won't allow them to engineer ways out of social problems.

http://wtec.org/ConvergingTechnologies

\section{Imbalance a sticky issue among stamps of distinction}

\section{David Adam, London}

As the acknowledged leader in your research field, you've earned the respect of colleagues, and that phone call from the Nobel prize committee will surely not be long in coming. But have you got what it takes to appear on a postage stamp? Very possibly, if you're a physicist in Germany, according to a new survey - but definitely not if you're a British mathematician.

Bob Jones, a retired chemist and keen stamp collector living in Meols in northwest England, scoured the entire philatelic output of Britain, France and Germany between 1951 and 1990 for sticky-backed science images.

"In an age where we no longer erect statues to our heroes, being celebrated on a postage stamp is an important mark of distinction," Jones says. "But most specialists think their own area is not properly represented."

Jones's trawl through national catalogues for the period discovered scientific images on $63(6.2 \%)$ of the 1,022 commemorative stamps issued in Britain. In France it was $\mathbf{8 5}$ (4.7\%) from 1,788 stamps, whereas science

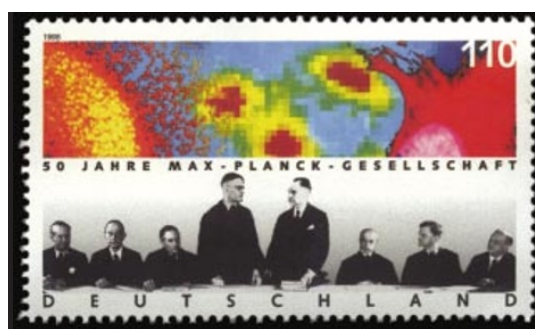

appeared on $49(3.6 \%)$ of the 1,365 stamps produced by the then West Germany.

Where science does appear, countries differ in their approaches. More than $80 \%$ of French science stamps in the survey celebrate individuals; in Germany the proportion is nearer two-thirds, whereas a mere one British science stamp in ten carries a portrait. This is perhaps in deference to Queen Elizabeth II, whose silhouette adorns every British stamp, encouraging designers to illustrate concepts, rather than people, in their work.

There are also different national partialities for particular disciplines. Biological science, including medicine, leads the way in the United Kingdom (on 33 stamps) and France (28 stamps), but appears

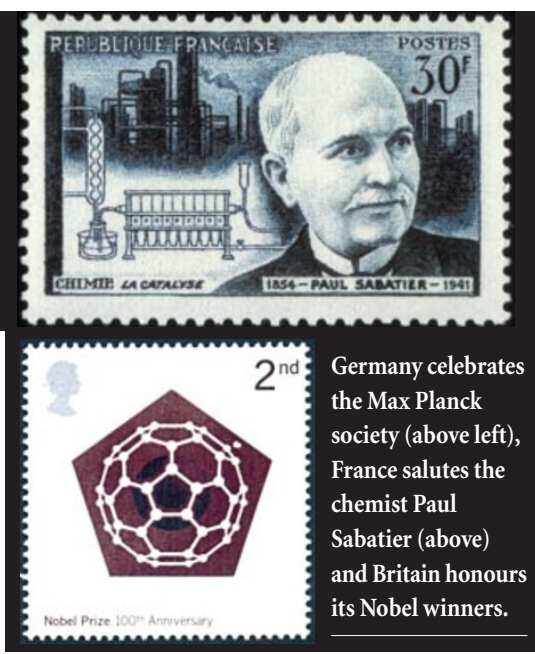

less often on German stamps (10) than do physics (33) and maths (12). Although British chemists have claimed 36 Nobel prizes, the subject has appeared only 13 times on the country's stamps. And UK mathematics or mathematicians haven't appeared once. 